\title{
Comentario sobre la noción colonial de "codicia". A propósito de la Dra. Elizet Payne Iglesias
}

\section{Commentary on the colonial notion of "greed." About Dr. Elizet Payne Iglesias}

\author{
José David Ramírez Roldán \\ Universidad de Costa Rica \\ San José, Costa Rica \\ jdr_r@hotmail.com
}

Recibido: 15/05/2019 Aceptado:12/09/2019

Resumen. El presente comentario está basado en la síntesis de investigaciones históricas estudiadas por la Dra. Elizet Payne Iglesias con respecto a la temática colonial de la explotación perlífera en regiones de América Latina. Asimismo, este artículo se realiza desde una perspectiva alternativa a la propuesta en la historiografía de la Dra. Payne, ya que analiza las tensiones creadas por la supuesta "codicia", relacionada con la figura del conquistador europeo durante la extracción de gemas (perlas) en las colonias del Nuevo Mundo.

Palabras clave: colonialismo, joyas, medio ambiente, América Latina, historiografía.

\begin{abstract}
This commentary is based on the historical research papers by Dr. Elizet Payne Iglesias regarding the colonial theme of pearl exploitation in Latin America. Also, this synthesis is made from an alternative perspective to the proposal in the historiography of Dr. Payne, since it analyzes the tensions created by the supposed "greed" related to the figure of the European conqueror during the extraction of gems (pearls) in the colonies of the New World.
\end{abstract}

Keywords: colonialism, jewelry, environment, Latin America, historiography. 
Revista Universidad en DiÁlogo • Vol. 10, N. ${ }^{\circ}$ 1, Enero-Junio, 2020 • 31-40

ISSN 2215-2849 • EISSN: 2215-4752

URL: http://www.revistas.una.ac.cr/index.php/dialogo/index CORREO ELECTRÓNICO: universidadendialogo@una.cr DOI: http://doi.org/10.15359/udre.10-1.2

Las perlas fueron unas gemas valiosas durante la época colonial, así como tantos otros recursos naturales extraídos de América, como el oro y la plata, sin embargo, su extracción en dicho contexto por medio del buceo tradicional de los pueblos aborígenes volvía aún más apreciable su obtención. Además, despertó la "codicia" de muchos comerciantes españoles al no ser un recurso común, debido a la lenta producción de las mismas por las ostras, pero sin conllevar un proceso de transformación para su comercialización, sino que valían en su estado natural a manera de joya. Por ende, no solo fueron visualizadas como un objeto útil para establecer un negocio lucrativo basado en redes mercantiles en puntos estratégicos, sino que como joyas representaban un símbolo de poder y riqueza en sí mismas, ya que las perlas fueron consumidas de manera suntuaria, siendo especialmente deseadas por mujeres de la clase alta.

El presente trabajo es un comentario basado en la síntesis de investigaciones académicas con respecto a la temática colonial de la explotación perlífera en regiones de América Latina desde una perspectiva alternativa a la propuesta en la historiografía de la Dra. Elizet Payne Iglesias. Por consiguiente, el objetivo de este trabajo es comprender el desarrollo histórico de los discursos utilizados por los conquistadores españoles, que tuvieran referencia a la noción de "codicia", con el fin de historizar dichas expresiones a propósito de las gemas encontradas en el Nuevo Mundo, específicamente, a lo desencadenado en torno a la explotación de perlas en Centro y Suramérica, ubicándose temporalmente en el periodo colonial.

Para efectos de la presente síntesis, este artículo se adentra en una manera de ver y hacer la Historia: proponiendo que dicha disciplina nos puede proporcionar un amplio panorama de perspectivas sociales y culturales en conjunto. En otras palabras, se podría decir que este es un estudio que analiza las tensiones creadas durante el periodo colonial por la supuesta "codicia", relacionada con la figura del conquistador español durante la extracción de gemas (perlas) en las colonias del Nuevo Mundo. Cabe señalar que el trabajo no es un intento por adentrarse en el campo de la historia conceptual o algún tipo de área similar, ya que se están estudiando las nociones presentes en las expresiones coloniales con respecto a sus formas más simples y comunes de entender la "codicia" dentro de un contexto colonial, por lo que no se propone una discusión semántica ni mucho menos analítica en términos conceptuales. 
URL: http://www.revistas.una.ac.cr/index.php/dialogo/index

CORREO ELECTRÓNICO: universidadendialogo@una.cr

DOI: http://doi.org/10.15359/udre.10-1.2

\section{La explotación perlífera en la historiografía de la Dra. Elizet Payne Iglesia}

La historiadora Elizet Payne Iglesias ${ }^{1}$ ha elaborado en dos de sus investigaciones un minucioso análisis histórico con perspectiva ambiental sobre la historia económica de la explotación perlífera, especialmente, durante la época colonial. Lo anterior es aún más interesante cuando se señala que esto lo realiza desde un ámbito espacial de escala local y regional.

El primer estudio de Payne con respecto a la pesca perlera fue defendido en el IX Congreso Centroamericano en Historia, celebrado en la Universidad de Costa Rica del 21 al 25 de julio del año 2008, titulado "Explotación perlífera en el Pacífico de Centroamérica (1522-1850)". En este trabajo se analiza la extracción de perlas en el Pacífico de Nicoya, Costa Rica, en la época colonial e inicios de la vida independiente. Asimismo, se rastrea el surgimiento de las redes sociales vistas como la herramienta principal que controlaba la comercialización de los bancos perlíferos, tanto en Panamá como en Costa Rica.

Uno de los aportes más valiosos de esta investigación es evidenciar la utilización cotidiana y religiosa de las perlas, además, logra indagar en las condiciones laborales, los pagos tributarios y las formas de explotación de la mano de obra esclava (indígena y negra) en la pesca perlera. Por último, se da una evidencia de cómo la extracción de perlas en el Golfo de Nicoya provocó un agotamiento de los bancos de ostras debido a la explotación indiscriminada en la zona.

El otro trabajo de Payne se titula "La explotación perlífera en el Centro y Sudamérica: una lectura desde la historia ambiental", el cual está incluido en la sección de "Economía y espacios" del libro Poder, economía y relaciones sociales en el reino de Guatemala (2014). Las características historiográficas de este texto son similares al anterior, siendo su objetivo de estudio la explotación perlífera vista en larga duración "desde el período precolonial americano, hasta las primeras cuatro décadas del siglo XX" (p. 50). Además, en la misma investigación se hace referencia a la extracción de nácar que posee la madre perla o perla madre, como también a la del tinte de caracol. Así, a diferencia del otro artículo, en este se abordan temas bioambientales

La Dra. Elizet Payne Iglesias es investigadora y profesora catedrática de la Escuela de Historia en la Universidad de Costa Rica, además sus estudios en su mayoría tratan temáticas económicas, políticas y sociales durante la época colonial de Costa Rica y Centroamérica, empero, en los últimos años de su carrera profesional ha estado situándose en contextos más recientes. 
Revista Universidad en DiÁlogo • Vol. 10, N. ${ }^{\circ}$ 1, Enero-Junio, 2020 • 31-40

ISSN 2215-2849 • EISSN: 2215-4752

URL: http://www.revistas.una.ac.cr/index.php/dialogo/index CORREO ELECTRÓNICO: universidadendialogo@una.cr DOI: http://doi.org/10.15359/udre.10-1.2

sobre el método de extracción y las condiciones ambientales del molusco para que se desarrollen las perlas, junto con algunos datos antropológicos de su pasado precolombino.

Otro tema detallado en los dos estudios de la Dra. Payne es la mancuerda simbiótica entre la "mano de obra indígena, esclavitud y extracción perlífera", dicha relación podría explorarse a fondo para futuros trabajos de investigación sobre el uso del buceo tradicional y sus efectos en la salud humana. Asimismo, se demuestran los diversos procesos en los que la Corona española sería visualizada como la máxima autoridad del poder central en condición de gobernabilidad para sus colonias, siendo los cuerpos esclavizados de los nativos americanos y negros quienes pagarían el precio del comercio perlífero.

Los conquistadores españoles se adentraron en las costas americanas del Pacífico en el año 1513 y, posteriormente, se centraron en explotar los bancos perlíferos existentes en las costas e islas de Venezuela y Colombia del mar Caribe. Asimismo, llegaron por medio de informes sobre la existencia de bancos perleros al actual territorio de América Central en las Islas de las Perlas (actual Panamá). En Nicoya (actual norte de Costa Rica), en 1522, se encontraron más opciones para el negocio de esta gema, por lo que en este contexto se crearon las primeras redes de explotadores y comerciantes de perlas bajo la administración de los conquistadores Gil González Dávila y Pedrarias Dávila (junto con sus respectivos descendientes), entre otros destacados personajes de la época.

Este negocio histórico durante la época colonial logró posicionar a los comerciantes para formar parte de la élite cartaginesa (Costa Rica) y nicaragüense, los cuales fueron asentados en Granada y Villa de Nicaragua (actual Rivas de Nicaragua), los mismos personajes utilizaron el Golfo de Nicoya y su costa pacífica como península para negociar estos productos. De hecho, las gemas que tenían una calidad más cotizada eran comercializadas y hasta obsequiadas en las cortes reales para las personas ricas o poderosas, en algunos casos, también fueron utilizadas en forma de joyas como promesas a algunas iglesias según sus distintos intereses personales (Payne, 2017a).

Como se ha dicho, los dos estudios de Payne fueron explorados desde una escala espacial que comparten en ambos casos un carácter regional, permitiéndonos así apreciar una de las primeras formas de explotación ambiental en la etapa colonial, entre el Nuevo y el Viejo Mundo. Pues la autora señala que la mayoría de conquistadores y comerciantes españoles estuvieron insertos en una lógica 
comercial de carácter regional, donde se adueñaron de los bancos perlíferos en el "Caribe de Venezuela y Colombia, así como, los localizados en el Pacífico sur de Centroamérica que comprende Panamá y Costa Rica, particularmente en Archipiélago de las Perlas en Panamá, la isla Coiba, el golfo de Nicoya y las costas del Pacífico de Costa Rica" (2014, p. 50). También, la escritora años después hace referencia a las costas de Manta en Ecuador, donde se encontraron perlas de baja calidad para competir con las extraídas de Panamá, además de aludir a la explotación sistemática y monopolizada de los bancos de ostras en La Española y Puerto Rico, donde sus comerciantes fueron respaldados por Reales Cédulas (2017b).

En este caso, la explotación perlífera se expresa mediante el saqueo de recursos naturales en regiones americanas colonizadas por poderosos imperios europeos, proceso que lleva a transformaciones en las mentalidades de sus impulsores. Por consiguiente, se está frente a una explotación dirigida hacia un mercado de compra y venta, donde sobresalen las vulnerabilidades de las sociedades colonizadas que promueven los lujos de la alta sociedad durante el control imperialista desde una lógica de extractivismo.

Dichos postulados se ponen en evidencia cuando "la extracción perlera en Cubagua alcanzó su apogeo entre 1530 y 1535; poco después se agotaron. Posteriormente, de Cubagua la actividad pasó a la isla Margarita (caribe de Venezuela) y a la costa continental de Venezuela y Colombia", por lo que "...hacia 1500 comenzaron también a escasear debido al uso intensivo y a la fuerte demanda en los mercados europeos" (Payne, 2017b, p. 636). En esta serie de casos, se evidencia cómo la explotación y las vulnerabilidades ecológicas de ciertas sociedades son usadas para promover un mayor control imperialista; pero finalmente dicho comercio puede llegar a su fin cuando los recursos naturales se agotan por forzar su producción en función del mercado.

El inicio de las empresas perleras en las Indias Occidentales era sucesor de un mercado milenario ya existente para el Viejo Mundo, donde originalmente los sitios perlíferos se localizaban y exhibían como joyas de lujo entre los círculos poderosos de las cortes del Medio Oriente, además de ser consideradas bastante atractivas en las élites de las civilizaciones mediterráneas, por lo que la aparición de las Indias Occidentales al poseer este recurso natural no tardó tiempo en reconocerse dentro de los círculos empresariales de comerciantes sevillanos desde el proceso del descubrimiento de América, ya que se supo que Cristóbal Colón durante su tercer viaje pudo conseguir algunas perlas por medio del trueque (Payne, 2017b). 
Revista Universidad en DiÁlogo • Vol. 10, N. ${ }^{\circ}$ 1, Enero-Junio, 2020 • 31-40

ISSN 2215-2849 • EISSN: 2215-4752

URL: http://www.revistas.una.ac.cr/index.php/dialogo/index CORREO ELECTRÓNICO: universidadendialogo@una.cr DOI: http://doi.org/10.15359/udre.10-1.2

\section{Rastreando la "codicia" del conquistador}

Como se ha visto, las investigaciones historiográficas de la Dra. Payne Iglesias sobre la explotación perlífera durante el periodo colonial plantean una lista de inquietantes posibilidades históricas que, antes de comentarse en su condición de trabajo novedoso -al ser investigaciones pioneras-, podrían explotarse aún más en el valor investigativo que deja la problemática desde otro tipo de perspectivas, con el fin de profundizar en otras aristas presentes de manera indirecta en la investigación.

Estas otras vías o tópicos del problema de estudio quizás no fueron explotados a profundidad, pero sí podrían analizarse desde otros puntos de vista desde las mismas fuentes empleadas o adicionales. Lo anterior tiene asidero en que la autora utiliza su material de estudio (fuentes primarias) según los intereses del momento; asimismo, bajo este panorama se podría considerar aún más productivo proponer otra forma de acercarse al problema de investigación, en lugar de oponerse a sus propuestas iniciales o solamente aceptarlas.

Así, el viaje aventurero del conquistador que desafía los distintos espacios remotos de las costas selváticas y mogollones del Nuevo Mundo, buscando prósperas recompensas (tierras, esclavos, oro, plata o joyas) por sus actos serviles a la Corona, pertenece a un relato cargado de odiseas hacia lo desconocido, todos relatos con capacidades útiles para estudiar pasajes que posean algún tipo de narrativa sobre sus trayectorias como colonizadores. Ya sea esto como en el caso de la heroica edad en que continuaba su travesía colonizadora el capitán general de Castilla del Oro y gobernador de Nicaragua, Pedro Arias Dávila (Segovia, 1468-León Viejo, 1531); el agotamiento hasta el cansancio por encontrar riquezas en un paraíso sin explorar (El Dorado o las minas de Tisingal); el sublime acto de evangelizar indígenas. Todos estos son episodios repetidos, comentados y compartidos de una u otra manera en la historia latinoamericana apoteótica, tradicional y episódica, tienen una descripción con respecto a las figuras de los colonizadores.

Un caso útil para comprender este fenómeno a profundidad son los hechos que se pueden encontrar en la actividad de la explotación perlífera en la época colonial, la cual generó tantas manifestaciones de "codicia" durante las travesías de empresas de conquista que se lideró una constante lucha entre los conquistadores por el mando del control de los bancos perleros y la mano de obra (indígena o negra) obligada a la extracción de la ostra perla. De esta odiosea conquistadora quedaron algunos rastros de este momento que tienen que ver con la obtención de este fascinante objeto (perlas), ya sea con un criterio recibido de forma perjudicial o provechosa. 
Para aclarar a lo que se hace referencia, en especial con respecto a lo relacionado con la "codicia" en los conquistadores europeos durante sus viajes al Nuevo Mundo, haciendo eco de las palabras del fraile español Francisco Ximénez, quien relataba que las gemas (las perlas) tienen tanto poder para causar fascinación que comentó: “Oh! Y que bien decía un mercader portugués a quien le vendían unas muy ricas perlas, no las quiero comprar, ni emplear en eso mi caudal, no sea que mañana amanezcan los hombres con juicio, y todo se me pierda" (Payne, 2017b, p. 635). Este fragmento evidencia el temor que representa el objeto "maldito" de "codicia", o sea, las perlas. Esta joya sería vista como un símbolo generador de locura entre los "hombres de bien", siendo apreciable la creación de una metáfora del aventurero que es seducido por la perversión de unas ricas perlas. Esa descripción del poder que representaban dichas joyas para pervertir tripulaciones completas descrita por aquel mercader portugués no era una idea tan lejana a lo que realmente sucedió por el control de los bancos perleros entre los colonos años más tarde.

De esta manera, hay que basarse en las palabras de la doctora Elizet Payne Iglesias, utilizando su investigación Las perlas de la reina: explotación perlifera en el Pacífico de Centroamérica (1522-1850) para evidenciar las manifestaciones de "codicia", y sobre esta misma línea se verán contextualizados los procesos sociales sucedidos. Por lo cual, se empieza a destacar que uno de los personajes más importantes de la explotación perlífera fue el famoso Hernán Cortés; asimismo, el conquistador de Nueva España reconocería los tesoros localizados en el llamado Mar de Cortés (hoy el Golfo de California). Mientras que en otros lados del mundo con respecto a las perlas se daba que

Los franceses e ingleses entraron en contacto con los pueblos del Pacífico Sur... En el siglo XVI, tal fue su impacto en Europa que pronto se convirtió en una de las actividades más acaparadas por los hispanos, hasta convertirse en uno de los rubros más importantes de explotación ambiental, antes de llegar a las vetas de oro y plata. (2017b, p. 637).

En la frase anterior se evidencia en qué momento se amplió el mercado de perlas, correspondiendo a la oferta y la demanda competitiva que se promovía por medio de la explotación socioambiental de las colonias. La función del mercado perlífero estaba localizada en los principales círculos de compra, los cuales fueron la joyería de lujo y el consumo religioso ceremonial. Además, normalmente este producto se mezclaba con piezas de oro como, por ejemplo, en los siguientes objetos: "anillos, zarcillos, arrasadas, relicarios, rosarios, en imágenes religiosas, cadenas, collares acompañadas de granates, diamantes 
Revista Universidad en DiÁlogo • Vol. 10, N. ${ }^{\circ}$ 1, Enero-Junio, 2020 • 31-40

ISSN 2215-2849 • EISSN: 2215-4752

URL: http://www.revistas.una.ac.cr/index.php/dialogo/index CORREO ELECTRÓNICO: universidadendialogo@una.cr DOI: http://doi.org/10.15359/udre.10-1.2

y hasta en el vestuario más fino. Hubo perlas en poder de la Iglesia, que se usaban en el vestuario y ornamento de los santos...". Por lo cual el comercio de perlas se unía y daba vida a otros mercados existentes.

En el caso centroamericano,

Las redes familiares y comerciales que se armaron alrededor de la extracción, comercialización y otras formas de trato de perlas, se prolongó a lo largo del periodo colonial. Las más altas autoridades españolas y la élite de Costa Rica, Nicaragua y de Guatemala, estuvieron involucradas en el tráfico de perlas... (Payne, 2017b, pp. 636-647)

Es evidenciada la manifestación de algún tipo de "codicia" por medio de las exigencias promulgadas por la Corona española sobre la expropiación y explotación del recurso perlífero. Esto sucedió en el caso de los habitantes de La Española (hoy República Dominicana) y de Puerto Rico que se apoderaron del negocio perlero en el Caribe, apoyados por medio de políticas imperiales para la explotación del medioambiente, registradas en las Reales Cédulas, razón por la que monopolizaron la explotación de los bancos de ostras para evitar la continua destrucción reproductiva de los bancos, debido a las manifestaciones de "codicia" descontrolada, puesto que

Al principio se obtuvieron mediante el trueque... El rey devengaba del quinto real unos 100,000 ducados solo de las pesquerías venezolanas, lo cual revela la importancia económica... Conociendo de esta nueva fuente de riqueza, Felipe II promulgó en 1591 un reglamento para la explotación racional de las perlas. (Payne, 2017b, p. 637).

\section{Epílogo}

Los estudios de la Dra. Elizet Payne Iglesias ya forman parte de la historiografía colonial de nuestras regiones latinoamericanas, en especial cuando de estudios novedosos se habla, aún más respecto a aquellos que mezclan diversos abordajes en la historiografía. Así, actualmente sus estudios sobre la explotación perlífera han ido madurando con el tiempo desde que dio su primer punto de partida, convirtiendo a sus investigaciones en cimientos y punto de referencia para los interesados en temas históricos de carácter bioambiental. 
En este sentido, se puede considerar que el estudio histórico de las sociedades humanas puede llegar a variarse en subdisciplinas que se complementen en diversas perspectivas conjuntas con respecto a un problema en concreto. Esto no es solamente válido como ejercicio científico, sino que es útil para incrementar la erudición sobre un problema en común, con el fin de brindar una mayor comprensión desde una serie de temáticas enriquecedoras.

Por ello mismo, insisto, actualmente el aporte de la Dra. Payne sigue siendo novedoso para una pronta actualización disciplinaria de la historia colonial. Asimismo, el presente trabajo buscó hacer lo mismo a menor escala temática desde las bases de una investigación aún más compleja, pero enriqueciendo un poco más la problemática de la explotación perlífera a través del tópico de las manifestaciones de "codicia" en los conquistadores con respecto a esta joya.

De esta manera, las posiciones de historiadores como Elizet Payne, pensadas y proyectadas desde un modelo de construcción científica más interdisciplinario, pero sin perder la identidad profesional, deja una gran lección sobre la historia y sus posibles alcances, siendo una disciplina que se concreta en el constante cambio, conocimiento y actualización de abordajes planteados en otros campos de estudio, atañendo en cada investigación al dilema del próximo avance científico para poder incorporarlo en una nueva perspectiva historiográfica que busca siempre estar innovando en su propia materia de estudio.

\section{Dedicatoria}

Dedicado a la memoria de Anthony Campos Delgado (1990-2014)

¿Con qué he de irme?

¿Nada dejaré en pos de mí sobre la tierra?

¿Cómo ha de actuar mi corazón?

¿Acaso en vano venimos a vivir, a brotar sobre la tierra?

Dejemos al menos flores.

Dejemos al menos cantos.

(Nezahualcóyotl, "Un recuerdo que dejo") 


\section{Referencias bibliográficas}

Payne, E. (2014). La explotación perlífera en el Centro y Sudamérica: una lectura desde la historia ambiental. En Velázquez, C. y Payne, E. (Coords.), Poder, economía y relaciones sociales en el reino de Guatemala (pp. 49-71). San José: EUCR.

Payne, E. (2017a). El Estado, la élite y las comunidades: los contratos en torno a la explotación de la madreperla en el Pacífico de Costa Rica (siglos XIX y XX). Anuario de Estudios Centroamericanos, (43), 225-255.

Payne, E. (2017b). Las perlas de la reina: explotación perlífera en el Pacífico de Centroamérica (1522-1850). Diálogos (Edición Especial en el IX Congreso Centroamericano en Historia del 2008), pp. 631-654. 